\title{
ЭКОНОМИЧЕСКИЕ И ИНСТИТУЦИОНАЛЬНЫЕ ИНТЕРЕСЫ КОММЕРЧЕСКИХ БАНКОВ В СОВРЕМЕННЫХ СОЦИАЛЬНО-ЭКОНОМИЧЕСКИХ УСЛОВИЯХ
}

\author{
(C) 2019 Мишин Алексей Юрьевич \\ Руководитель подкомитета по защите прав кредиторов \\ Комитета по финансовым услугам Деловой России \\ Общероссийская общественная организация «Деловая Россия» \\ 119121, Москва, 2-й Вражский переулок, д. 1 \\ E-mail: Alink2501@gmail.com
}

В статье рассматривается актуальная проблема взаимодействия экономических и институциональных интересов коммерческих банков, исследуются причины возникающих противоречий. Доказывается необходимость трансформации институциональной среды банковского сектора в целях повышения качества предоставляемых банковских услуг, что обусловливает рост конкурентоспособности реального сектора экономики, что особенно необходимо в условиях санкционного давления и нарастания угрозы экономической безопасности страны. Обоснованы предложения и рекомендации по совершенствования институциональных отношений, в том числе за счет повышения доверия хозяйствующих субъектов к ключевым институтам финансового сектора.

Ключевые слова: банк, институт, доверие, институциональная среда, экономические интересы, институциональные интересы.

В настоящее время, в период нарастания геополитической напряженности, все чаще возникающих экономических кризисов, растет внимание экономистов, экспертов, научного сообщества к монетарному сегменту, который в текущий момент начинает играть всю большую роль не только в регулировании показателей денежного обращения, но и в функционировании системы общественного воспроизводства.

Такой повышенный интерес к вопросам экономических интересов коммерческих банков связан с одной стороны, с глобальной трансформацией социально-экономической системы в период становления цифровой модели экономики, с другой же - обусловлен особенностями развития российской банковской системы в настоящий момент. В процессе осуществления банковской деятельности неизбежно возникают противоречия в экономических и институциональных интересах, что детерминируется, прежде всего, самой их спецификой. Так, экономические интересы коммерческих банков направлены на получение максимальной прибыли, что возможно только при условии соблюдения всех необходимых финансовых показателей, обеспечивающих рентабельность банка, снижение его рисков, поддержание соответствующего уровня ликвидности, достаточности собственных средств и других показателей. Так же реализация экономических интересов коммерческих

банков делает необходимым совершенствование их деятельности, особенно в период становления новой цифровой модели экономики, что проявляется во внедрении новых финансовых продуктов, технологий, освоении онлайн пространства и т.д.

Немаловажное значение в целях роста прибыльности коммерческого банка играет и внешняя экспансия, рост количественных показателей за счет расширения географических масштабов бизнеса, привлечения новых клиентов и т.п. Помимо указанных направлений реализация экономических интересов ориентирована на рост собственного капитала банка, что в условиях проводимой регулятором достаточно жесткой монетарной политики представляется особенно актуальным. Повышение показателя ликвидности коммерческого банка становится крайне важной задачей, так как функционирующая в настоящая время банковская система имеет значительные ограничения фондирования, связанные с недоступностью внешних, относительно недорогих финансовых ресурсов, что накладывается на общую пассивность иностранных инвесторов, а также факторы эндогенного характера, такие как снижение потребительского спроса, узость национального финансового сектора и его высокая монополизация. Все вышеперечисленные проблемы реализации экономических интересов коммерческих банков не 
позволяют им в полной мере осуществлять необходимые функции по обеспечению реального сегмента экономики доступными финансовыми ресурсами, что становится серьезным тормозом экономического роста.

Экономические интересы коммерческих банков в полной мере могут быть реализованы только при условии удовлетворения общественных потребностей, то есть потребностей клиентов, рассчитывающих на получение финансовых ресурсов. Обеспечение частных индивидуальных интересов в дальнейшем приводит к реализации общественных интересов, направленных на сохранение банковской системы в целом. Как справедливо полагает А. Смит «Не от благожелательности мясника, пивовара или булочника ожидаем мы получить свой обед, а от соблюдения ими своих собственных интересов» [1]. Выполняя общественно значимые функции, банки аккумулируют сбережения населения в инвестиции, что способствует развития промышленного производства, созданию общественных благ и т.д. Уровень капитализации банковской системы, эффективность ее функционирования обеспечивают в целом потенциал развития всей хозяйственной системы. Банки как институт являются проводниками осуществляемой правительством денежно-кредитной политики, следовательно, обеспечивают реализацию оставленных целей, направленных на достижение стабильности инфляции, экономического роста и занятости населения [3].

В процессе своей деятельности банки, с одной стороны формируют свои собственные экономические интересы, с другой - обеспечивают интересы государства, предприятий, населения. Увеличивая доходность своих клиентов в краткосрочной и долгосрочной перспективе, банки реализуют свои экономические интересы. Во многом успешность функционирования банка зависит от того, насколько удовлетворены его клиенты - кредиторы и заемщики. Если речь идет о кредиторах банка, то в первую очередь их интересует сохранности и приумножение собственных денежных средств. Предприятия, открывая счета в банках, рассчитывают на быстроту проведения операций, культуру обслуживания, минимальный размер комиссии, программу лояльности для постоянных клиентов и другие приятные бонусы.

Наибольший потенциал для реализации экономических интересов банков имеет кредито- вание, так как именно эта сфера деятельности составляет активные операции банка, позволяющие извлекать прибыль. Однако, в настоящее время, проводимая регулятором жесткая денежно-кредитная политика, направленная на таргетирование инфляции сдерживает банковское кредитование. Кроме того, реализуемый императив концентрации ресурсов банковского сегмента привели к существенному сокращению количества коммерческих банков. Так, в течение пяти лет с 2015 года число кредитных организаций сократилось больше чем в два раза. В 2015 г. их было 1708, в то время как на 01.01.2019 года уже 709. По размеру уставного капитала наибольшее количество кредитных организаций сосредоточенно в группе, имеющей уставной капитал от 90 до 300 млн. руб. [2]. На наш взгляд подобное сокращение создает определенные трудности с получением кредита основной массой юридических лиц, которые в условиях достаточно низкого значения коэффициента монетизации экономики России испытывают значительный дефицит денежных средств.

Теоретической базой осуществляемой денежно-кредитной политики ЦБ РФ являются представления монетаристов, полагающих, что излишняя денежная масса, поступающая в обращение приведет к бесконтрольному росту цен, что раскрутит спираль инфляции. Однако, это не совсем так. Определяющее значение имеет то, в какой сфере аккумулируется избыточное денежное предложение. Если речь идет о потреблении домашних хозяйств, то, скорее всего, оно действительно способно привести к росту темпов инфляции. Но это правило не действует в случае целенаправленного размещение денежных средств в конкретных отраслях, связанных с производством благ, как правило, капиталоемких. Жесткие нормативные требования ЦБ к кредитным организациям существенным образом тормозят создание новых предприятий, малой формы бизнеса, так как ими они нуждаются в предоставлении относительно дешевых финансовых ресурсов. От этого страдает и сама банковская система, которая вынуждена быть ограниченной в реализации кредитных операций, которые занимают основной удельный вес в структуре доходов коммерческих банков. По мнению многих экспертов в области денежно-кредитной политики критерием ее эффективности является не темп инфляции, а обеспеченность экономических агентов деньгами, 
стабильно низкие трансакционные издержки получения кредита, качество использования сбережений населения. Доступность кредитов составляет необходимое условие инновационного развития социально-экономической системы.

В странах с развитой экономикой используются различные стимулирующие механизмы, направленные на увеличение кредитования реального сектора экономики, например, субсидирования, государственных гарантий и поручительств. В российских условиях подобные мероприятия не находят должного отражения, и такой поддержки явно не хватает, как самой банковской системе, так и предприятиям, производящим готовую продукцию. Вместе с тем, не редки случаи, когда банки ведут себя недобросовестно, нарушая все принципы конкуренции, используют мошеннические схемы, игнорируя интересы своих клиентов, демонстрируя ярко выраженное оппортунистическое поведение. Подобная политика отдельных коммерческих банков нарушает не только экономические, но и институциональные интересы общества, так как подрывает стабильность институциональной среды финансовой системы. В этой связи наиболее остро стоит вопрос о нахождении оптимальных пропорций между регулированием банковской деятельности и воспроизводством конкурентных принципов функционирования банковской системы и недопущении ее монополизации [4]. Одним из основных вопросов дальнейшего совершенствования банковского законодательства является вопрос об оптимальном сочетании в банковском праве частных интересов банков, их клиентов и общественных интересов.

Противоречие экономических и институциональных интересов коммерческих банков может существенным образом дестабилизировать целостность банковской системы, что может отразиться на потенциале развития всей социально-экономической системы. для достижения равновесия необходимо создания эффективно функционирующей институциональной среды, то есть набора соответствующих институтов, обеспечивающих защиту интересов разнообразных хозяйствующих субъектов. Представители научного сообщества не раз отмечали, что эффективно действующие институты создают условия для экономического роста, снижают размер трансакционных издержек, уменьшают неопре- деленность и риски. Следовательно, с одной стороны, субъекты заинтересованы в реализации своих частных эгоистических потребностей, с другой - они осуществляют действия, направленные на удовлетворение институциональных потребностей. Так, Ф. фон Хайек утверждал, что хотя люди сами участвуют в создании институтов, таких как институт денег, собственности, конкуренции, обмена, государства и т.д., все они были созданы не по умолчанию, а стихийно. Не размышления людей, а их жизненная потребность породила подобные вещи [5].

Таким образом, институт выступает некой формой целенаправленного согласования разнообразных интересов хозяйствующих субъектов, что формирует обобщенный институциональный интерес. Институциональный интерес представляет собой направленность действий акторов на формирование институтов, основным функциональным свойством которых является создание и воспроизводство институциональной среды. В свою очередь институциональная среда обеспечивает реализацию экономических интересов хозяйствующих субъектов, путем координации их деятельности, в результате соблюдения определенных правил, закрепленных формальными и неформальными нормами. Реализация институционального интереса заключается в извлечении выгод от соблюдения норм и правил, а также поиск, а затем и создание новых институтов, регламентирующих поведение субъектов, что способствует снижению трансакционных издержек, и облегчает проблему выбора.

Институты возникают непосредственно в процессе взаимодействия людей, которые стремятся реализовать институциональные интересы, что может быть достигнуто только при условии некоторого подчинения частных эгоистических интересов общественным. Соответственно, институциональной интерес коммерческого банка - это его действия, направленные на формирование, воспроизводство и изменение институтов во времени и пространстве, которые создают основу для эффективного функционирования институциональной среды, обеспечивая при этом реализацию экономических интересов банков путем выработки определенных правил и рамок поведения, при согласовании с имеющимися у них альтернативами [6].

Следует понимать, что каждый субъект хозяйственных отношений является одновре- 
менно носителем и частного и общественного институционального интереса. Частный институциональный интерес состоит в желании создать такой институт, который бы обеспечивал максимизацию выгод именно данному субъекту. Общий институциональный интерес представляет собой направленность действий всего общества на формирование институционального порядка, обеспечивающего целостность экономической среды и возможность реализации экономических интересов многочисленных субъектов. Сложности взаимодействия частных и общественных как экономических, так и ин- ституциональных интересов порождают порой противоречивые действия, как самих коммерческих банков, носителей частных интересов, так и мегарегулятора, как агента обобщенного общенационального экономического и институционального интереса. Полагаем, что грамотное согласование разнообразных интересов коммерческих банков и Центрального Банка обеспечит формирование новой модели их взаимодействия, что создаст условия для реализации политики, направленной на экономический рост и повышения уровня благосостояния населения России.

\section{Библиографический список}

1. Смит А. Исследование о природе и причинах богатства народов. Москва. 1962.

2. Статистика Банка России [электронный ресурс] - Режим доступа: http://cbr.ru/statistics/print.aspx?file=bank system/group_19.html\&pid=lic\&sid=itm_23162

3. Рязанова О.Е., Левченко Л.В. Инвестиционный климат как условие развития инновационной экономики // Экономические науки. 2014. № 114. С. 14-28.

4. Ларионова А.В., Коновалова М.Е. Роль интеллектуального капитала в современном кризисе банковской системы РФ. // Вестник Самарского экономического университета. 2017. № 12(158). С..5-7.

5. Хайек Ф. .Пагубная самонадеянность. Ошибки социализма. Москва. 1992. С. 345.

6. Михайлов А.М. проблемы реализации экономических и институциональных интересов собственников факторов производства: монография. Москва. Экономические науки, 2006. С. 34. 